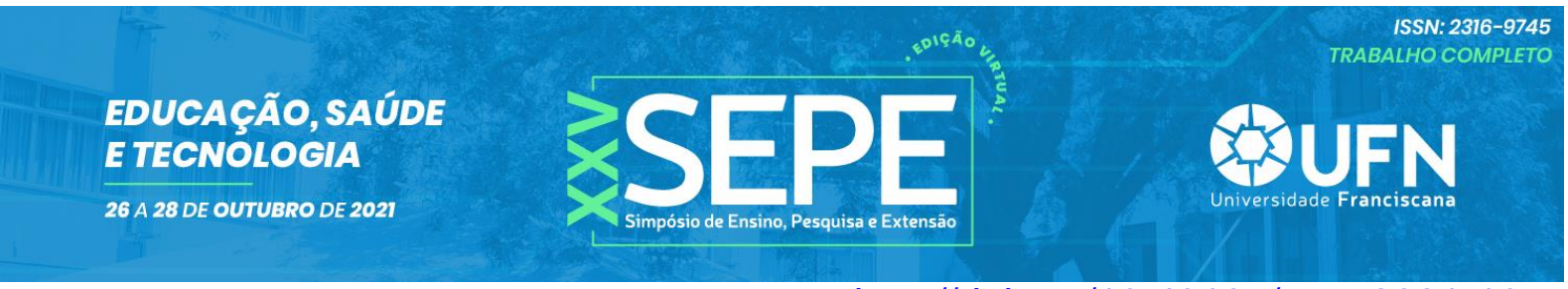

http://doi.org/10.48195/sepe2021-105

\title{
INFOGRÁFICO SOBRE A CONSTRUÇÃO DO CONHECIMENTO INTERPROFISSIONAL EM SAÚDE
}

\author{
Márian Oleques Pires'; Eduardo Jorge Yamada²; Luana Pizarro Meneguello; \\ Marcia Regina Canto Michelotti 4; Andressa Caetano da Veiga5; Dirce Stein
}

Backes

\section{RESUMO}

Objetiva-se relatar a experiência de construção de um infográfico sobre estratégias prospectivas de construção do conhecimento interprofissional. Trata-se de um relato de experiências construído a partir das discussões teórico-práticas da disciplina de Prática Orientada do Mestrado de Saúde Materno Infantil, fundamentadas no pensamento da compelxidade de Edgar Morin. Desenvolveu-se, a partir dessas discussões, um produto técnico, do tipo infográfico, com a finalidade de fomentar o conhecimento interprofissional no trabalho em saúde. Conclui-se enfatizando a relevância da construção do saber interprofissional em saúde. É de fundamental importância que os profissionais de saúde se percebam autores e protagonistas na integração do conhecimento, na conexão de saberes, na empatia, na capacidade de lidar com as incertezas e de reencontrar a missão na complexa teia de relações e interações profissionais.

Palavras-chave: Práticas de Saúde; Educação; Pesquisa.

Eixo Temático: Atenção Integral e Promoção à Saúde.

\section{INTRODUÇÃO}

A obra "A cabeça bem-feita" leva o leitor a uma reflexão de como a pesquisa e o ensino na academia tornaram essas entidades limitadas, devido à lógica enraizada do ensino cartesiano. Tal cerceamento às entidades de ensino acarretam uma imersão em seus círculos, separando o estudo de um fenômeno em pequenos fragmentos isolados (MORIN, 2000).

O apagamento da análise de pequenas partes de um fenômeno desconsiderado sua influência do todo e vice-versa, impossibilita uma visão global do estudo do fenômeno. Em outros termos, impede a visualização da complexidade dos 
fenômenos em estudo, independentemente de sua área (MORIN, 2000).

A abordagem do pensamento complexo do autor Edgar Morin pode ser aplicada sobre diferentes perspectivas de áreas, sobretudo na área da saúde, partindo do conceito de saúde e viver saudável. Podemos conceituar a saúde por um sistema dinâmico, singular e auto-organizado, social, que objetiva promover um viver saudável de um indivíduo, família e comunidade (BACKES et al., 2016).

Apesar do conceito de saúde incluir todos os âmbitos da vida de um ser humano, a formação dos profissionais de saúde não foi historicamente construída e atualizada, segundo a relação complexa da saúde e seus cuidados. Como na lógica cartesiana, os conteúdos foram fragmentados e organizados, com aulas focadas no professor especialista na posição central do processo de ensino-aprendizagem, em contraposto a promoção da saúde (DE SOUZA, 2020).

Neste contexto, a teoria da complexidade do autor Edgar Morin foi amplamente debatida durante as aulas da disciplina "Prática Orientada" do Mestrado em Saúde Materna Infantil. A partir das aulas pode-se repensar a maneira de como a ciência é produzida e ensinada assim como a refinação das práticas de saúde atuais no ambiente de trabalho de cada colega.

Como resultado das reflexões entre os colegas, elaborou-se então um material contento estratégias que podem ser usadas no ensino na área da saúde e no atendimento aos pacientes, principalmente na área hospitalar, de modo a suprimir o reducionismo e a fragmentação e melhorar a satisfação de todos os participantes (pacientes e equipes multidisciplinares).

Objetiva-se neste estudo relatar a experiência de construção de um infográfico sobre estratégias prospectivas de construção do conhecimento interprofissional.

\section{METODOLOGIA}

Trata-se de um estudo do tipo relato de experiências construído a partir das discussões teórico-práticas na disciplina de "Prática Orientada" do Mestrado de Saúde Materno Infantil. O estudo possui carater multidisciplinar, incluindo aproximadamente 20 participantes em cada dia de aula contendo profissionais das áreas de: 
Enfermagem, Medicina, Fisioterapia, Odontologia, Educação Física e Tecnologia da Informação.

A partir do relato de experiência dos colegas, sobre melhores práticas no seu ambiente de trabalho por meio do referêncial de Edgar Morin, desenvolveu-se um produto técnico, do tipo infográfico, com a finalidade de fomentar o conhecimento interprofissional no trabalho em saúde.

\section{RESULTADOS E DISCUSSÕES}

A partir do relato de experiencia dos colegas, destacaram-se cinco pontos a serem debatidos de acordo com Edgar Morin, sendo esses explorados no infográfico conforme demonstrado na Figura 1.

Figura 1: Infográfico descritivo de estratégias interprofissionais em saúde

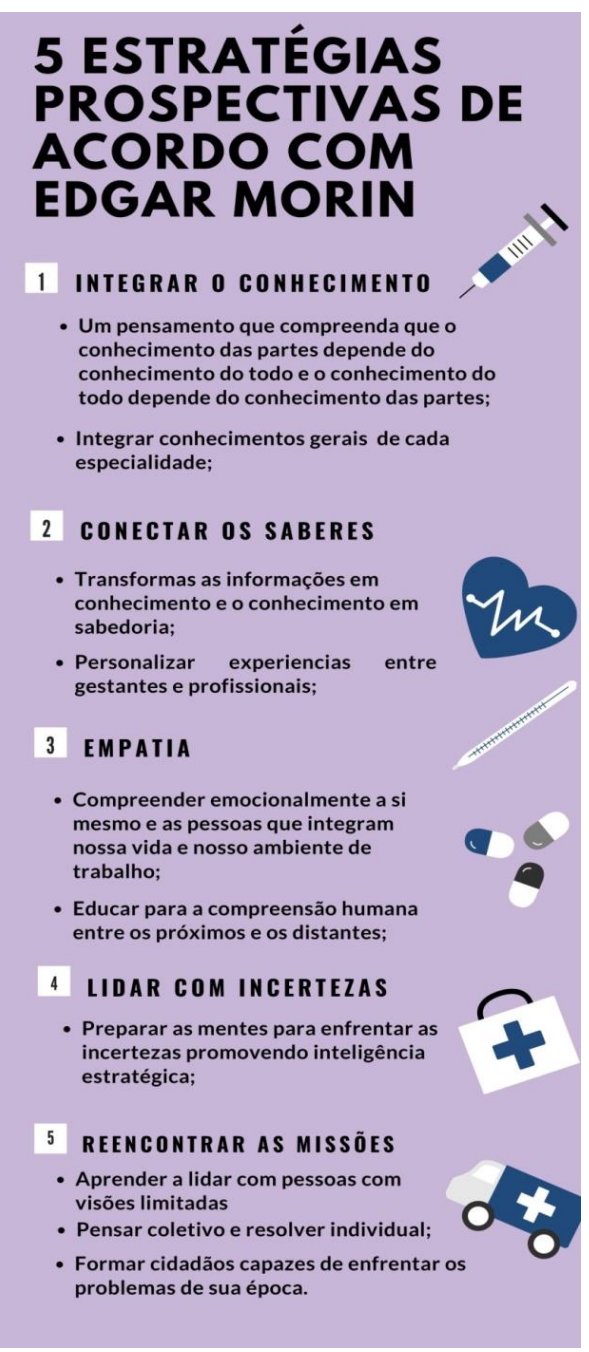


Fonte: Autores

O primeiro ponto relatado entre os colegas se inseriu na prática de integrar conhecimentos. São relatadas dificuldades em um ambiente de trabalho onde, um especialista desconhece os aspectos das outras áreas para a qual presta auxílio. Segundo relato de experiencia de um dos autores do estudo:

\begin{abstract}
"Um anestesiologista não deve só conhecer as minúcias de sua especialização, mas deve também conhecer o básico de cada especialidade de modo a prover o melhor atendimento possível ao paciente. Podemos citar algumas formas de atingir esse objetivo: capacitações globais de um bloco cirúrgico/bloco obstétrico, capacitações cruzadas entre setores do hospital, roleplaying, simulações" (Autor 1).
\end{abstract}

Diante da discussão da prática de integrar conhecimentos, surgiram relatos da necessidade de conectar os saberes, diante da falta de informação e desconhecimento dos pacientes sobre suas operações e tratamentos e a necessidade do profissional de saúde passar esse conhecimento. Debateu-se, nessa direção, o nervosismo de gestantes quando é necessária a realização de um parto cesáreo. Tal fato ocorre devido muitas vezes à falta de informações sobre o processo cirúrgico ou o fornecimento de informações errôneas por parentes/conhecidas(os).

O estado de medo acarreta consequências nefastas para o processo cirúrgico, aumentando a morbidade da gestante e do recém-nascido, gerando por vezes angústia e estresse pós-traumático (MELLO, 2021). Como solução para amenizar o problema foi pensado na implantação de um Ambulatório de Pré-Anestésico Obstétrico nos mesmos moldes de Ambulatório de Pré-Anestésico Geral.

O terceiro ponto definido foi a empatia, caracterizada como a capacidade psicológica de sentir o que sentiria outra pessoa, caso estivesse na mesma situação vivenciada por ela (SOUZA, 2020). Em 2019 uma resolução da Comissão Nacional de Residência Médica (CNRM) instituiu uma nova matriz de competências com o acrônimo CHA (Conhecimentos, Habilidades, Atitudes) (Resolução CNRM n¹1, de 8 de Abril de 2019), decorrida da constatação que os egressos dos programas de especialização encerravam-na sem a formação humana necessária para o seu exercício completo, tanto na relação com pacientes como também com outros profissionais. 
Na área de saúde não há um treinamento para se lidar com as incertezas em relação à perda de pacientes ou resultados indesejados, causando angústia e sofrimento aos profissionais (COUCEIRO, 2019). Viu-se a necessidade em se estabelecer condições para que os egressos dos cursos da área da Saúde estejam aptos a desenvolver resiliência quando os resultados sejam negativos.

Práticas como simulações de "no win, no victory" com o objetivo de fomentar a discussão sobre perdas inevitáveis no atendimento, poderiam auxiliar esse profissional. Neste contexto, definiu-se o último ponto analisado, "reencontrar a missão", onde o profissional aprende a importância do coletivo, a olhar para dentro de si mesmo e relembrar as razões pelas quais escolheu a arte de ajudar o próximo.

\section{CONCLUSÃO}

Conclui-se enfatizando a relevância da construção do saber interprofissional em saúde. É de fundamental importância que os profissionais de saúde se percebam autores e protagonistas na integração do conhecimento, na conexão de saberes, na empatia, na capacidade de lidar com as incertezas e de reencontrar a missão na complexa teia de relações e interações profissionais.

Profissionais sem essa gama ampliada de conhecimentos, habilidades e atitudes se tornam incapazes de atuar em prol de um sistema de saúde mais eficiente e ao mesmo tempo mais humano. Assim, torna-se importante reformular os currículos dos cursos da área da saúde, de modo a incluir aspectos de resiliência, empatia e compartilhamento de conhecimento e sabedoria. 


\section{QUFN}

\section{REFERÊNCIAS}

BACKES, Dirce Stein et al. Interatividade sistêmica entre os conceitos interdependentes de cuidado de enfermagem. Aquichan, v. 16, n. 1, p. 24-31, 2016.

COUCEIRO, Flavia Braga Lopes et al. A perceção da morte e do morrer por estudantes de medicina. Diálogos Interdisciplinares, v. 8, n. 10, p. 1-13, 2019.

DE MELLO, Rafaela Saragiotto Ferreira et al. Medo do parto em gestantes. FEMINA, v.49 n.2 p.121-128, 2021

DE SOUZA, Cinoélia Leal et al. Ambiente na formação em saúde: Reflexões sobre hiperespecialização do ensino baseada em Edgar Morin. Brazilian Journal of Development, v. 6, n. 7, p. 53513-53527, 2020.

MORIN, Edgar. A cabeça bem-feita. Rio de Janeiro: Bertrand Brasil, v. 99, 2000. SOUZA, Loraine et al. A empatia como instrumento para a humanização na saúde: concepcões para a prática profissional. REVASF, Petrolina- Pernambuco - Brasil, vol. 10, n. 21 , p. $148-167,2020$ 